\title{
Construction of Agricultural Products with Geographical Indications from the Perspective of Interest Connection Mechanism
}

\author{
Yewei Song ${ }^{*}$, Xiujuan $\mathrm{Li}^{2}$, Ling Tan $^{3}$, Qingqiu Wang ${ }^{4}$, Zhiqiang Tao ${ }^{5}$ \\ ${ }^{1}$ Department of Asset Evaluation, Sichuan Agricultural University, Dujiangyan, Chengdu, Sichuan, China, \\ 611830 \\ ${ }^{2}$ Electronic Business, Sichuan Agricultural University, Sichuan, China, 611830 \\ ${ }^{3}$ School of Architecture and Urban and Rural Planning, Sichuan Agricultural University, Chengdu, Sichuan, \\ China,611830 \\ ${ }^{4}$ Marketing, Sichuan Agricultural University, Sichuan, China, 611830 \\ ${ }^{5}$ Male Sichuan Agricultural University Business School, Chengdu, Sichuan,611830 \\ *Corresponding Author email: 914977980@qq.com
}

Keywords: Geographical indication agricultural product interest link mechanism rural revitalization

\begin{abstract}
The construction of agricultural products with geographical indications is one of the important ways to promote rural revitalization, and it has a very positive significance to help the countryside build a well-off society in an all-round way. By studying the characteristics of geographical indication agricultural products and the current situation of geographical indication agricultural products industry, this paper finds out the internal links of the industrial chain of geographical indication agricultural products, and, from the perspective of leading enterprises, farmers and rural cooperatives, creates a new type of mechanism for linking interests to promote the construction of geographical indication agricultural products, which will help rural areas get out of poverty and achieve rural revitalization.
\end{abstract}

\section{Introduction}

Agricultural geographical indication is an important carrier of agricultural traditional superior resources and a concentrated embodiment of local characteristic brands. Building a brand of agricultural products with geographical indications is an important measure to strengthen the brand of farmers in the strategy of rural revitalization. This study is mainly from the internal development of geographical indications of agricultural products, focusing on the creation of a new interest linkage mechanism, the geographical indications of agricultural products brand building and development of the internal driving force.

Interest connection mechanism is a mechanism that links the interests of multiple subjects through a certain agreement. Its forms are mainly divided into free sale, contract linking interest mechanism, joint-stock cooperation linking interest mechanism and so on. At present, there are abundant researches on the mechanism of interest connection. Scholars also find out the problems existing in the existing mechanism of interest connection by coincidence, and put forward corresponding solutions according to specific problems. However, through field visits, we find that most of the schemes put forward by scholars provide directional guidance. In practice, the relevant organizations or institutions are often unable to start. Therefore, how to proceed from the existing problems of interest linkage mechanism and propose a specific and operable solution has become our research. The theme of the study. 


\section{Current status of geographical indications agricultural products brand}

1)Production area

Due to the different natural geographical conditions suitable for the growth and development of agricultural products, there are obvious geographical differences in the distribution of space. Different regions and the number of structural varieties and quantities produced are different, and the production area is significant.

2)Product uniqueness

The product quality of geographical indication agricultural products mainly depends on the local natural environment, including weather, soil, etc.. These unique growth environments have created the unique quality of geographical indication agricultural products. For example, Pujiang citrus is known for its unique varieties, which is different from other citrus varieties.

3)Long context

Most of the geographical indications of agricultural products have a long history of human factors, the formation of the brand is often not achieved overnight, but through long-term historical precipitation or with ancient and modern celebrities have close ties and interesting stories.

4)The use of publicity, the separation of the two powers

The trademark characteristic of geographical indication agricultural product brand is the separation of ownership and right of use.[1] Most of the ownership of Agricultural Geographical Indications brand belongs to the collective or the government, but the relevant individuals can enjoy the right to use as long as they have been authorized to license, which makes the ownership of geographical indications of agricultural products brand different from other trademarks, it does not have exclusive or exclusive, the use of public characteristics is remarkable.

\section{Problems faced by geographical indications of agricultural products}

\subsection{Seasonal agricultural products are strong}

The most important thing in geographical indications is planting crops, such as vegetables and tea.[2] Although fruits and vegetables can be bought in almost every season with the advancement of science and technology, due to the limitations of natural conditions and consumers'preferences in different seasons, such as preferring to consume watermelons in summer rather than winter, the marketing time of the same or even similar types of agricultural products is almost the same. The sale time of such products is generally short and will be severely restricted by natural geographical conditions. Therefore, the primary agricultural products and general agricultural products now as geographical indication brands will compete for a limited consumer market in the same sales time.

\subsection{Geographical indications of agricultural products homogenization serious}

The primary agricultural product market can be approximated as a fully competitive market, which means that it is very easy for competitors to enter and exit the market, there are numerous substitutes, there are a large number of buyers and sellers, which also leads to the geographical indication brand agricultural products want to enter from the product innovation is not particularly easy.

\subsection{The brand names of primary agricultural products do not attract enough attention}

According to the survey, many consumers in Pujiang County know the county's landmark products, but in the process of purchasing will not pay too much attention to whether the products purchased are landmark brands.

\subsection{Many geographical indications of agricultural products have begun to develop regional markets}

For example, Anyue lemon is sold to Japan and other East Asian countries in large quantities. Pujiang Ugly Mandarin is also popular in Singapore, Malaysia and other Southeast Asian countries. 


\subsection{The government's propaganda is insufficient, and the competition between farmers and enterprises is also one of the reasons why the development of geographical indication brand has been hindered}

As can be seen from the above, primary agricultural products are facing a grim situation, on the one hand, the government has not played a role in making production and distribution activities and market demand to make the most appropriate coordination, on the other hand, the product itself and production and operation mode of unsystematic also led to the development of the status quo.

\section{Discover problems}

\subsection{Leading enterprises are weak}

The leading enterprises of geographical indication products are the important influencing factors of building geographical indication brand and the key to promoting the industrialization of agriculture. At present, most leading enterprises authorized by geographical indications of agricultural products show the characteristics of small quantity and low degree of deep processing.[3 ]

These enterprises have little effect on the development of geographical indication brand and the enrichment of farmers, but their actual driving ability is weak. Leading enterprises aim to maximize their own interests, so that many government-supported project results are internalized by enterprises, not radiated to the relevant farmers.

\subsection{Loose interest linkage mechanism}

The existing interest linkage mechanism between leading enterprises and farmers of geographical indication products mainly includes contract interest linkage mechanism, cooperative interest linkage mechanism and joint-stock cooperative interest linkage mechanism. These three mechanisms have some drawbacks in system and management.[4]

According to the main data bulletin of the Third National Agricultural Census of Pujiang County, $87.5 \%$ of the agricultural production and business operators are educated in junior middle schools or below, $86.0 \%$ of the agricultural production and business operators are educated in junior middle schools or below among large-scale agricultural households, because most farmers are insensitive to the market. It is easy to misestimate the market and produce conflicts with enterprises, such as the early picking of Kiwifruit in Pujiang County. On the other hand, enterprises have strong market judgment. Some enterprises use their foresight and farmers'low cultural level to squeeze and exploit farmers, and between farmers and enterprises, despite the market principles. The interest links collapsed.

\subsection{Brand awareness of agricultural products is weak.}

China's geographical indications of agricultural products are often dependent on wholesale circulation to the market, but there is basically no unified logo and packaging in the products, consumers can not distinguish their origin and varieties and other relevant information, making consumers even for the quality of products have a high degree of recognition, but can not form loyalty to the brand. The weak brand awareness of geographical indications makes the demand of agricultural products fluctuate greatly, and the price fluctuates accordingly. Even the agricultural products with organic certification of geographical indications can not have a competitive advantage. 


\section{The solution to the problem of brand construction of agricultural products geographical indications}

\subsection{Improve the interest linkage mechanism}

Among the many existing interest linking mechanisms, cooperative alliance-based interest linking mechanism is the most widely used and covers a wide range, but there are many problems such as how to deal with the interest linking between cooperatives, as well as the weak interest linking mechanism between cooperatives and farmers.

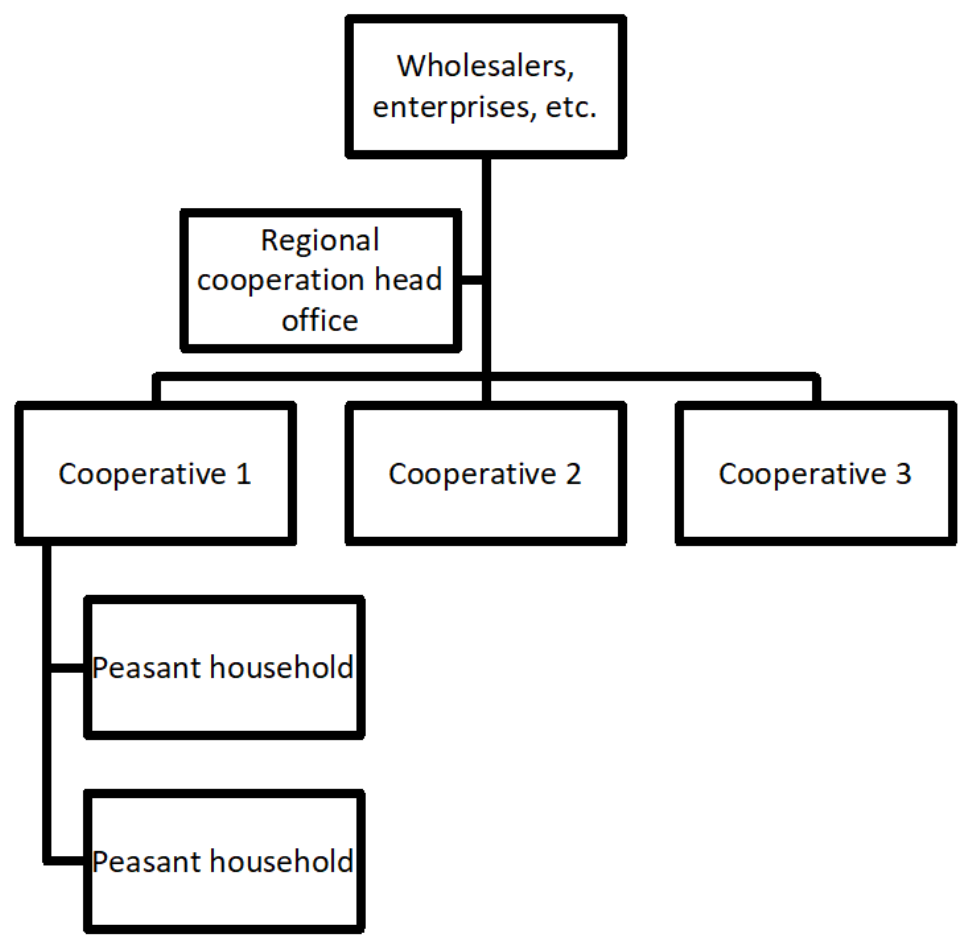

union + Schematic diagram of interest linkage mechanism of classified stock system

The alliance alliance system is divided into two levels.

The first level is the interest link among cooperatives, which is established by the relevant government departments, trade associations and cooperatives spontaneously. Each cooperative joins the cooperative in the form of shares. The stock evaluation criteria are evaluated according to the output, quality and existing sales situation of each cooperative.

Within the second-level cooperatives, the joint-stock system was adopted in order to strengthen the links, because the former mechanism of interest links was weak.

\subsection{Develop and expand leading enterprises}

1)Actively develop and train a large number of large backbone enterprises with strong driving force and strong strength.

First of all, the government needs to implement relevant measures.[5] Internally, the internal mechanism of enterprises should be constantly improved: promoting integration, high efficiency, diversification, and the development of "three modernizations" enterprises. The introduction of fresh blood and technology to promote enterprise development and enhance the core competitiveness of existing enterprises.[6] Secondly, in view of the existing "small scale, weak strength, weak competitiveness" and other issues, efficient management and supervision.

2)Improve relevant policies and build "investment guarantee mechanism for leading enterprises".

On the financial side, the government has given sufficient financial support, increased subsidies to leading enterprises, actively participated in various projects to obtain funds for the development of enterprises; on the land side, improved homestead and other issues, rational distribution of leading 
enterprises'land, so that leading enterprises can buy land at the same time, they can also own. There are construction bases.

3)The standardization of professional cooperatives to deepen the organization of agricultural production and operation.

Collecting the "scattered" cooperatives in the same area, relevant governments and associations to conduct unified training and product quality certification; standardizing the management and construction of professional cooperatives, for the development of good cooperatives for reference, the development of backward cooperatives to improve in time.

4)Keep pace with the pace of innovation and enhance core competitiveness. Introduce "enterprise + electricity supplier + Internet +" way.Improve the previous production mode, innovate production ideas, introduce new production mode, improve the efficiency of production cultivation.[7]

5)Gradually carry out standardized production and expand the construction of standardized bases.

Explore the production base, farmers and leading enterprises of the interests of the linkage mechanism to form a "leading enterprise + individual farmers + base" model. Taking the construction of standardized production base as the breakthrough point, enterprises should be guided to innovate the mode of order agriculture and form an integrated connection with individual farmers by directional input and service.[8]

\subsection{Raising farmers' own level}

The government actively and regularly dispatches agricultural technicians to the countryside to conduct "one-to-one" technical training for farmers so as to remedy their deficiencies in knowledge. At the same time, it will strengthen farmers'awareness and perception of geographical indications of agricultural products brand, and promote farmers to produce according to brand standards.[9]

\subsection{Developing intermediary organizations}

Intermediary organization is the link between enterprises and agriculture. Form an intermediary organization among the cooperatives, coordinate and standardize the production and management of the cooperatives, and contact enterprises and cooperatives; form a standardized intermediary organization among farmers, promote the ties between enterprises and farmers, shorten the distance between the two, so that enterprises in the acquisition, contracted land, and agricultural products acquisition. And processing is more convenient.

\section{References}

[1] Belletti G , Marescotti A , Vakoufaris H , et al. Linking protection of geographical indications to the environment: Evidence from the European Union olive-oil sector[J]. Land Use Policy, 2015, 48:94-106.

[2] Rippon M J . What is the geography of Geographical Indications? Place, production methods and Protected Food Names[J]. Area, 2014, 46(2):154-162.

[3] Marievivien D , Garcia C A , Kushalappa C G , et al. Trademarks, geographical indications and environmental labelling to promote biodiversity: The case of agroforestry coffee in India[J]. Development Policy Review, 2014, 32(4):379-398.

[4] Khanna M , Roe B E , Vercammen J , et al. Strength of Protection for Geographical Indications: Promotion Incentives and Welfare Effects[J]. American Journal of Agricultural Economics, 2014, 96(4):1030-1048.

[5] Likoudis Z , Sdrali D , Costarelli V , et al. Consumers' intention to buy protected designation of origin and protected geographical indication foodstuffs: the case of $\mathrm{G}$ reece[J]. International Journal of Consumer Studies, 2016, 40(3):283-289.

[6] Besky S . The labor of terroir and the terroir of labor: Geographical Indication and Darjeeling tea plantations[J]. Agriculture \& Human Values, 2014, 31(1):83-96. 
[7] Fu Jing, Xiang Qiulan. Comments on the Development Thought of Circular Economy Clustering [J].Exploration of Economic Problems, 2010 (12): 14-19.

[8] Tan Zian. SWOT analysis of peanut production in Tongren area [J]. Guizhou Agricultural Sciences, 2009, 37 (7): 225-228.

[9] Sun Yanan, Hu Hao. Study on the development strategy of geographical indications agricultural products [J]. economy, 2015 (7): 81-84. 